\title{
Resource-saving preparation of the 38KHGNM steel surface for heading of automobile components
}

\author{
Aleksey Filippov ${ }^{1 *}$, German Pachurin ${ }^{1}$, Diana Goncharova ${ }^{1}$, Gor Gevorgyan ${ }^{1}$, Mariia \\ Mukhina $^{2}$, Irina Trunova $^{1}$, and Natalia Koniukhova ${ }^{1}$ \\ ${ }^{1}$ Nizhny Novgorod State Technical University named after R.A. Alekseyev, Minin Street, 24, Nizhny \\ Novgorod, 603950, Russia \\ ${ }^{2}$ Minin Nizhny Novgorod State Pedagogical University, Ul'janova street, 1, Nizhny Novgorod, \\ 603950, Russia
}

\begin{abstract}
To produce high-quality fasteners for motor group components of automobiles it is necessary to follow the increased requirements to calibrated rolled stock in terms of surface defects. Therefore, the goal of this paper is to study the reasons, types and depth of the surface defects on the calibrated rolled stock from steel 38KHGNM Ø $12.0 \mathrm{~mm}$ on the basis of the metallographic analysis. Before cold upsetting, the hot-rolled products are subjected to metal flow and removal of unacceptable surface defects by means of expensive turning operation during which the screw cuts and cracks might appear. It has been defined, that the hot-rolled stock from steel, grade 38KHGNM, diameter $12.0 \mathrm{~mm}$ has nonuniform mechanical properties, grooves, laps and partial decarburization on the surface. The heat treatment of the rolled stock with a decarburized layer on the surface contributes to its further decarburization. Poor alignment of calibrated stock during its turning at the turning machine does not enable to completely remove the decarburized layer with minimum skinning of rolled stock. It has been shown that the use of rolled stock from steel 38KHGNM with surface defects and unreasonably high decarburized layer on the surface increases its rejection by $8 \%$ and raises the consumption of rolled stock for manufacturing of important fasteners for the motor group of automobiles.
\end{abstract}

\section{Introduction}

The most important task in the production development is the improvement of quality of the initial metal products and parts made therefrom, increase of their performance, reliability, durability, as well as bringing of these indicators to the world levels in order to ensure the products competitiveness at the world market [1-3].

The automotive fasteners made from calibrated rolled stock by cold upsetting refer to the most important components in mechanical engineering [4-6].

\footnotetext{
*Corresponding author: mariyamuhina@yandex.ru
} 
The increased requirements in terms of surface defects - their depth and the presence of a decarburized layer are applied to calibrated rolled stock used for cold die forging [7-9]. It is relevant for fasteners used in the components of the motor group of automobiles [10, 11].

Rolled gas blowholes, hair seams, laps and others refer to surface defects of rolled stock. A negative defect in the hot-rolled and calibrated rolled stock surface is the presence of a decarburized layer [12], which significantly worsens its mechanical properties, since the surface becomes susceptible to the formation of grooves and scratches [13]. GOST norm 10702-78 "Profiles made of carbon and alloy high-quality structural steel for cold extrusion and upsetting" specifies the requirements to the presence of defects and decarburized layer on the rolled product surface and their permissible values.

Before cold upsetting, the hot-rolled stock is subjected to plastic deformation [14] and removal of unacceptable surface defects by means of expensive turning operation [15]. During the calibrated rolled stock surface turning, the unwanted surface defects occur. In this type of technological operation, the straight round nose cutters are used in a thin surface layer, which causes hardening of the surface layer and the appearance of high temperatures. Screw cuts and cracks may appear on the surface of a turned rolled stock. In addition, poor alignment at Kieserling machine leads to uneven skinning of the calibrated rolled stock surface around the circumference, and the decarburized layer and defects on the surface remain of unacceptable size.

During manufacture of fasteners for automobile engines, the 38HGNM steel is often used. Prepared for cold upsetting, the calibrated rolled products must meet the following requirements of GOST 19702-78: $\delta_{\mathrm{B}}=600 \mathrm{MPa}$, HB hardness < 207, value of decarburized layer $<0.05 \mathrm{~mm}$, the surface quality should correspond to group E of GOST 14955-77, that is, individual risks are allowed with a depth of not more than half of the maximum deviation in diameter.

The results of the incoming inspection often do not provide $100 \%$ information about the quality status of the entire batch of the delivered rolled metal product. Table 1 shows the results of the incoming inspection of hot-rolled stock of steel $\varnothing 12.0 \mathrm{~mm}, 38 \mathrm{KHGNM}$ grade manufactured by "Mechel” OJSC (city of Chelyabinsk).

Table 1. Results of the incoming inspection of hot-rolled stock.

\begin{tabular}{|c|c|c|c|c|c|c|c|c|c|}
\hline \multicolumn{10}{|c|}{ Incoming inspection } \\
\hline $\begin{array}{l}\text { Steel } \\
\text { grade }\end{array}$ & $\begin{array}{c}\varnothing, \\
\mathrm{mm}\end{array}$ & Batch & $\begin{array}{c}\text { Mass, } \\
\mathrm{kg}\end{array}$ & $\begin{array}{c}\text { Number of } \\
\text { bundle }\end{array}$ & $\begin{array}{l}\delta \text { в, } \\
\text { MPa }\end{array}$ & $\begin{array}{l}\delta \\
\%\end{array}$ & $\begin{array}{l}\Psi \\
\%\end{array}$ & $\mathrm{HB}$ & Upset \\
\hline \multirow{6}{*}{$\begin{array}{c}38 \\
\text { KHGNM }\end{array}$} & \multirow{6}{*}{12,0} & \multirow[b]{3}{*}{ No. 1} & \multirow[b]{3}{*}{17642} & \multirow[b]{3}{*}{40} & 599 & 35 & 71.5 & 149 & \multirow{3}{*}{$\begin{array}{c}\text { Upsetting test up to } 1 / 2 \mathrm{H} \\
\text { and upsetting test up to } 1 / 3 \\
\mathrm{H} \text { samples passed }\end{array}$} \\
\hline & & & & & 549 & 33 & 64.2 & 156 & \\
\hline & & & & & 562 & 35 & 67.6 & 149 & \\
\hline & & \multirow{3}{*}{ No. 2} & \multirow{3}{*}{12461} & \multirow{3}{*}{28} & 550 & 25 & 67.3 & 156 & \multirow{3}{*}{$\begin{array}{c}\text { Upsetting test up to } 1 / 2 \mathrm{H} \\
\text { and upsetting test up to } 1 / 3 \\
\mathrm{H} \text { samples passed }\end{array}$} \\
\hline & & & & & 567 & 26.7 & 68.7 & 149 & \\
\hline & & & & & 633 & 28.3 & 65.2 & 156 & \\
\hline
\end{tabular}

Conclusions on the results of the incoming inspection:

1. Hot rolled stock of $38 \mathrm{KHGNM}$ steel of $\varnothing 12.0 \mathrm{~mm}$ has been delivered in annealed condition.

2. The microstructure of rolled metal products of batch No. 1 and No. 2 corresponds to GOST 10702-78 - the structure of granular pearlite. 
3. Batch No. 1 of metal rolled products does not comply with GOST 10702-78, since one sample has the laps of $0.1 \mathrm{~mm}$ deep and on the second sample the lap is $0.09 \mathrm{~mm}$ (Fig. 1). The laps on the rolled products surface are not allowed.

Batch No. 2 of the rolled products complies with GOST 10702-78; a groove, $0.1 \mathrm{~mm}$ deep has been detected on one sample.

4. Batch No. 1 of rolled products does not comply with GOST 10702-78, since the depth of decarburized layer (fine grain, partial decarburization) is $0.2 ; 0.4$ and $0.5 \mathrm{~mm}$. Batch No. 2 of metal rolled products does not comply with GOST 10702-78, since the depth of the decarburized layer (fine grain, partial decarburization) is $0.35 ; 0.4$ and $0.4 \mathrm{~mm}$. The allowable value of the hot-rolled stock decarburized layer is $1.5 \%$ of the rolled stock diameter $(0.015 \times 12.0=0.18 \mathrm{~mm})$.

5. The chemical composition of hot-rolled stock of 38KHGNM $\varnothing 12.0 \mathrm{~mm}$ steel corresponds to GOST 10702-78 and is presented in Table 2.

Table 2. Chemical composition of 38KHGNM Ø $12.0 \mathrm{~mm}$ steel.

\begin{tabular}{|c|c|c|c|c|c|c|c|c|}
\hline \multirow{2}{*}{ Steel grade } & \multicolumn{7}{|c|}{ The composition of elements in \% } \\
\cline { 2 - 9 } & $\mathrm{C}$ & $\mathrm{Mn}$ & $\mathrm{Si}$ & $\mathrm{P}$ & $\mathrm{S}$ & $\mathrm{Cr}$ & $\mathrm{Ni}$ & $\mathrm{Mo}$ \\
\hline 38 KHGNM & $\begin{array}{l}0.37- \\
0.43\end{array}$ & $0.7-1.0$ & $0.17-0.37$ & $\leq 0.035$ & $\leq 0.035$ & $0.4-0.6$ & $0.4-0.7$ & $0.15-0.25$ \\
\hline
\end{tabular}

It has been found that hot rolled stock of 38KHGNM steel with a diameter of $12.0 \mathrm{~mm}$ has nonuniform mechanical properties, partial decarburization, grooves and laps on the surface. An example of the "lap" type surface defect in hot rolled stock is presented in Fig. 1, "rolled gas blowholes" - in fig. 2, and "grooves" - in Fig. 3.

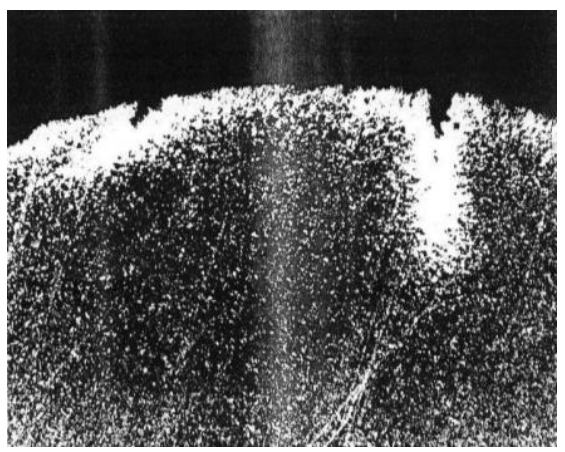

Fig.1. Laps at the surface of hot-rolled stock of 38KhGNM steel. Transverse microsection. Etching by $4 \% \mathrm{HNO}_{3}$ in alcohol. Magnification x200.

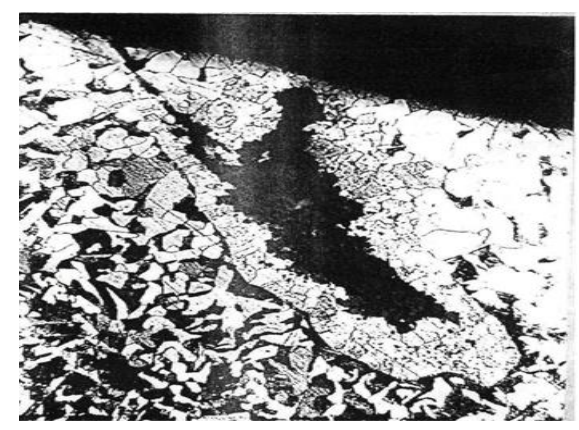

Fig 2. Rolled gas blowhole at the surface of stock material. Transverse microsection. Etching by $4 \%$ HNO3 in alcohol. Magnification x100. 


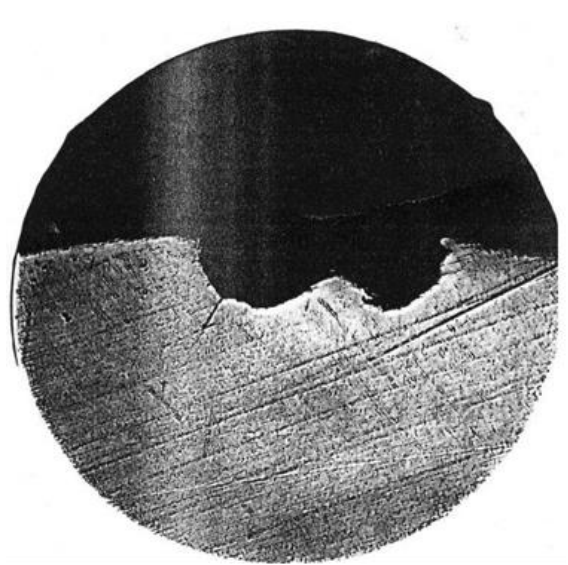

Fig. 3. Grooves on the surface of hot rolled metal. Unetched transverse microsection. Magnification $\mathrm{x} 100$.

The pilot production of such metal products has been started for further calibration according to two technological options:

\section{Option 1}

1. Initial hot rolled stock of 38KHGNM steel of $12.0 \mathrm{~mm}$ diameter.

2. Etching of hot-rolled stock in a sulfuric acid solution.

3. Calibration of hot-rolled stock from $12.0 \mathrm{~mm}$ to $11.4 \mathrm{~mm}$ diameter (degree of compression - $10 \%$ ).

4. Annealing of calibrated rolled stock with a diameter of $11.4 \mathrm{~mm}$ in protective-gas furnaces.

5.Etching of calibrated rolled stock with a diameter of $11.4 \mathrm{~mm}$ in a sulfuric acid solution.

6. Turning of calibrated rolled stock from $11.4 \mathrm{~mm}$ to $10.35 \mathrm{~mm}$ diameter, followed by calibration to a diameter of $10.15 \mathrm{~mm}$ (degree of compression - 4\%).

7.Phosphating of calibrated rolled stock, diameter $10.15 \mathrm{~mm}$.

\section{Option 2}

1. Initial hot rolled stock of 38KHGNM steel of $12.0 \mathrm{~mm}$ diameter.

2.Etching of hot-rolled stock in a solution of sulfuric acid.

3. Calibration of hot-rolled stock from $12.0 \mathrm{~mm}$ to $11.4 \mathrm{~mm}$ in diameter (degree of compression of $3 \%$ ).

4. Turning of calibrated rolled stock from $11.4 \mathrm{~mm}$ to $10.40 \mathrm{~mm}$ in diameter, followed by calibration to a diameter of $10.15 \mathrm{~mm}$ (degree of compression of 5\%).

5. Phosphating of calibrated rolled stock of $10.15 \mathrm{~mm}$ diameter.

Etching of hot-rolled stock was carried out in a pickling bath with a concentration of $\mathrm{H}_{2} \mathrm{SO}_{4}$ solution being $22.6 \%, \mathrm{Fe}_{2} \mathrm{SO}_{4}-8 \%$ with the addition of an inhibitor and sodium chloride during 1.2 hours with intermediate washing.

Bundles of hot-rolled and calibrated rolled stock were calibrated at the BC-1/750 mill, annealed in protective gas furnaces and turned with subsequent calibration at Kieserling machines. The results of heat treatment in protective gas furnaces are shown in Table 3. 
Table 3. The results of heat treatment of calibrated rolled stock of 38HGNM steel in protective-gas furnaces.

\begin{tabular}{|c|c|c|c|c|c|}
\hline \multirow{3}{*}{$\begin{array}{l}\text { Seq } \\
\text { No. }\end{array}$} & \multirow{3}{*}{ Batch } & \multirow{3}{*}{ Diameter, mm } & \multicolumn{3}{|c|}{ Test results } \\
\hline & & & \multirow{2}{*}{$\delta_{\mathrm{B}}, \mathrm{MPa}$} & \multicolumn{2}{|c|}{ Decarburized layer, $\mathrm{mm}$} \\
\hline & & & & General & Free-ferrite \\
\hline \multirow{3}{*}{1} & \multirow{3}{*}{ No. 1} & \multirow{3}{*}{11.2} & 585 & 0.3 & 0.15 \\
\hline & & & 576 & 0.3 & 0.1 \\
\hline & & & 561 & 0.4 & 0.2 \\
\hline \multirow{3}{*}{2} & \multirow{3}{*}{ No. 2} & \multirow{3}{*}{11.2} & 598 & 0.4 & 0.2 \\
\hline & & & 561 & 0.3 & 0.2 \\
\hline & & & 567 & 0.25 & 0.2 \\
\hline
\end{tabular}

The general decarburization to the depth of $0.25-0.4 \mathrm{~mm}$, to pure ferrite $0.1-0.2 \mathrm{~mm}$ was detected on the tested samples of annealed calibrated rolled stock of $11.2 \mathrm{~mm}$ diameter.

After turning and calibration at the Kieserling machine, the depth of the decarburized layer and the mechanical properties of the rolled products were monitored after treatment completion based on both technologies. The results of the production control of the calibrated rolled stock of 38KHGNM steel $\varnothing 10.15 \mathrm{~mm}$ in accordance with technology No. 1 and technology No. 2 are listed in Table 4.

Table 4. The results of production control of calibrated rolled stock of $\varnothing 10.15 \mathrm{~mm}$.

\begin{tabular}{|c|c|c|c|c|c|c|c|c|c|}
\hline \multirow[b]{3}{*}{ No. } & \multirow[b]{3}{*}{$\begin{array}{l}\text { Number of } \\
\text { process } \\
\text { treatment }\end{array}$} & \multirow[b]{3}{*}{$\begin{array}{c}\varnothing, \\
\mathrm{mm}\end{array}$} & \multicolumn{7}{|c|}{ Test results } \\
\hline & & & \multirow[b]{2}{*}{$\begin{array}{c}\delta_{\mathrm{B}}, \\
\mathrm{MPa}\end{array}$} & \multirow[b]{2}{*}{$\begin{array}{l}\Psi, \\
\%\end{array}$} & \multirow[b]{2}{*}{$\begin{array}{l}\delta \\
\%\end{array}$} & \multirow[b]{2}{*}{ Surface condition } & \multicolumn{3}{|c|}{ Decarburized layer, $\mathrm{mm}$} \\
\hline & & & & & & & General & $\begin{array}{l}\text { Local } \\
\text { partial }\end{array}$ & 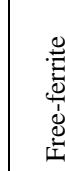 \\
\hline \multirow{4}{*}{1} & \multirow{4}{*}{ No.1 } & \multirow{4}{*}{10.15} & 685 & 59.4 & 34.2 & \multirow{4}{*}{$\begin{array}{l}\text { Mechanical damage } \\
\text { to the depth of } 0.025 \\
\text { mm. Upsetting test } \\
\text { passed }\end{array}$} & no & no & no \\
\hline & & & 660 & 62.3 & 30.2 & & 0.2 & 0.1 & 0.1 \\
\hline & & & 713 & 62.4 & 30.2 & & no & no & no \\
\hline & & & 647 & 63.7 & 29.8 & & 0.35 & - & 0.15 \\
\hline \multirow{4}{*}{2} & \multirow{4}{*}{ No. 2} & \multirow{4}{*}{10.15} & 659 & 64.7 & 23.7 & \multirow{4}{*}{$\begin{array}{l}\text { Mechanical damage } \\
\text { to the depth of } 0.01 \\
\text { mm. Upsetting test } \\
\text { passed }\end{array}$} & no & no & no \\
\hline & & & 660 & 67.1 & 26.4 & & no & no & no \\
\hline & & & 602 & 64.7 & 28.3 & & no & no & no \\
\hline & & & 602 & 67.6 & 25.5 & & no & no & no \\
\hline
\end{tabular}

It has been established that the microstructure of calibrated rolled stock of 38KHGNM steel of $10.15 \mathrm{~mm}$ diameter is granular perlite, in the transition stage to granular with ferrite (Fig. 4). 


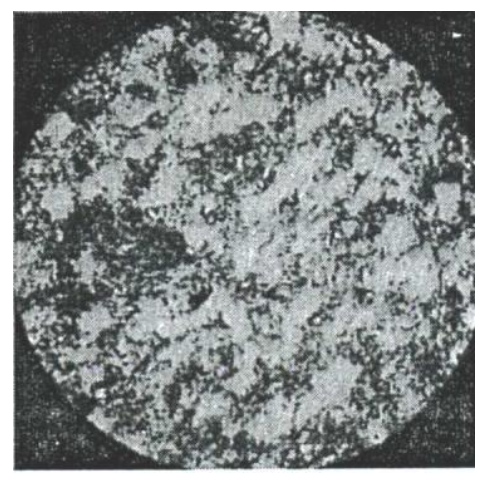

Fig. 4. Microstructure of calibrated rolled stock of 38KHGNM steel of $10.15 \mathrm{~mm}$ diameter.

In accordance with GOST 10702-78, a decarburized layer is not allowed on calibrated rolled stock made from previously turned calibrated rolled stock. Calibrated rolled stock manufactured based on technology No. 1 has general decarburization to the depth of 0.2$0.35 \mathrm{~mm}$, local partial decarburization to the depth of $0.1 \mathrm{~mm}$, decarburization to pure ferrite of 0.1-0.15 mm. No surface defects were found.

The main reasons for a decarburized layer presence on a calibrated rolled stock of $\varnothing$ $10.15 \mathrm{~mm}$, manufactured according to technological option No. 1 are the following:

1. The presence of a decarburized layer to the depth of $0.5 \mathrm{~mm}$ at the initial hot rolled stock of 38KHGNM Ø $12.0 \mathrm{~mm}$ steel.

2. The presence of a general decarburized layer, up to $0.4 \mathrm{~mm}$ deep and a decarburized layer to pure ferrite, up to $0.2 \mathrm{~mm}$ deep after heat treatment in protective-gas furnaces.

3. Poor alignment of calibrated rolled stock during turning at the Kieserling machine.

\section{Conclusions}

1. The use of hot-rolled stock with surface defects and an increased value of the decarburized layer on the surface increases its rejection and increases the consumption of rolled stock by $8 \%$ during the production of fasteners for the motor group of automobiles.

2. Heat treatment of calibrated rolled stock having a decarburized layer on the surface contributes to further decarburization of the rolled stock surface.

3. Poor alignment of calibrated stock during its turning on the turning machine does not enable to completely remove the decarburized layer with minimum skinning of rolled stock.

\section{References}

1. G.V. Pachurin, A.A. Filippov, et al., IOP Conf. Series: Materials Science and Engineering, 632, 012037 (2019) DOI:10.1088/1757-899X/632/1/012037

2. G.V. Pachurin, N.A. Kuz'min, et al., Russian Engineering Research, 39, No. 7, 577579 (2019) DOI: 10.3103/S1068798X19070153

3. G.V. Pachurin, D.A. Goncharova, et al., Material Sci \& Eng., 3(6), 195-199 (2019) DOI:10.15406/mseij.2019.03.00113

4. A.A. Filippov, G.V. Pachurin, et al., IOP Conf. Series: Materials Science and Engineering, 632, 012010 (2019) DOI:10.1088/1757-899X/632/1/012010

5. A.A. Filippov, G.V. Pachurin, et al., Met Sci Heat Treat, 61(7), 517-520 (2019) https://DOI.org/10.1007/s11041-019-00455-6 
6. A.N. Kuzmin, A.A. Filippov, et al., AAE IOP Conf. Series: Materials Science and Engineering, 695, 012030 (2019) DOI:10.1088/1757-899X/695/1/012030

7. G.A. Gevogian, R.A. Vorobyev, et al., Scopus International Scientific Electric Power Conference, IOP Conf. Series: Materials Science and Engineering, 643, 012127 (2019) DOI:10.1088/1757-899X/643/1/012127

8. G.V. Pachurin, A.A. Filippov, et al., Journal of Physics: Conference Series, 1353, 012087 (2019) DOI:10.1088/1742-6596/1353/1/012087

9. A.A. Filippov, G.V. Pachurin, et al., IOP Conf. Series: Materials Science and Engineering, 632, 012010 (2019) DOI:10.1088/1757-899X/632/1/012010

10. G.V. Pachurin, S.M. Shevchenko, et al., IOP Conf. Series: Materials Science and Engineering, 327 (2018) 032040 doi:10.1088/1757-899X/327/3/032040.

11. A.A. Filippov, G.V. Pachurin, et al., Metallurgist, 59, 9-10, 810-815 (2016) DOI: 10.1007/s11015-016-0177-y

12. A.A. Filippov, G.V. Pachurin, et al., Ferrous Metallurgy, 61, No.7, 551-556 (2018) DOI: $10.17073 / 0368-0797-2018-7-551-556$

13. A.A. Filippov, G.V. Pachurin, et al., Repair. Recovery. Modernization, 11, 38-42 (2019) DOI: 10.31044/1684-2561-2019-0-11-38-42

14. G.V. Pachurin, A.A. Filippov, Steel in Translation, 38, № 7, 522-524 (2008) DOI: 10.3103/S096709120807005X

15. A.A. Filipov, G.V. Pachurin, et al., ICI2AE 2019, IOP Conf. Series: Materials Science and Engineering, 632, 012010 (2019) DOI:10.1088/1757-899X/632/1/012010 